\title{
Ortaöğretim Öğrencilerinde Problemli İnternet Kullanımının Yalnızlık ve Psikolojik İyi Oluş ile İlişsisinin İncelenmesi*
}

\author{
Investigating the Relationship between Problematic Internet Use \\ and Psychological Well Being and Loneliness in Secondary Education \\ Students
}

DOI $=\underline{10.17556 / j i f .58322}$

\author{
Dursun MERAL ${ }^{* *}$, Hüseyin Hüsnü BAHAR ${ }^{* * *}$
}

Özet

Araştırmanın amacı okul türü ve cinsiyetin Problemli İnternet Kullanımını (PİK) etkileyip etkilemediğini belirlemek, Psikolojik İyi Oluş (PİO) ve yalnızlığın PİK'in anlamlı bir yordayıcısı olup olmadığını tespit etmektir. Çalışma grubunda Anadolu Lisesi ve İmam Hatip Lisesinde öğrenim gören 242 ortaöğretim öğrencisi bulunmaktadır. Veri toplama aracı olarak Problemli İnternet Kullanım Ölçeği-Ergen (PİKO-E), Psikolojik İyi Oluş Ölçeği (PİOÖ-E) ve UCLA yalnızlık ölçeği kullanılmıştır. PİK puanlarının cinsiyet ve okul türüne göre anlamlı ölçüde değiştiği tespit edilmiştir. Sınıf-okul türü ortak etkisi ile cinsiyet-sınıf-okul türü ortak etkisinin de PİK puanlarında etkili olduğu bulunmuştur. Psikolojik İyi Olma (PIO) ve yalnızlık puanlarının PIKK puanlarının anlamlı bir yordayıcısı olduğu belirlenmiştir. PİO puanları PİK puanlarını pozitif yönde yordarken yalnızlık puanları PİK puanlarını negatif yönde yordamaktadır.

Anahtar kelimeler: Problemli internet kullanımı, Yalnızlık, Psikolojik iyi olma, ortaöğretim öğrencileri

\section{Abstract}

The purpose of the study was to determine whether school type and gender affected Problematic Internet Use (PIU) or not, and to specify whether Psychological Well-Being (PWB) and loneliness were significant predictors of PIU. In the study group, there were 242 secondary education students studying at

\footnotetext{
${ }^{*}$ Bu çalışmada Doç. Dr. Hüseyin Hüsnü Bahar danışmanlığında, Dursun Meral tarafından hazırlanan Yüksek Lisans Seminer çalışması sürecinde toplanan veriler kullanılmıştır.

** Rehber Öğretmen, Erzincan Üniversitesi Sosyal Bilimler Enstitüsü, Yüksek Lisans Öğrencisi

*** Doç. Dr., Erzincan Üniversitesi Eğitim Fakültesi Eğitim Bilimleri Bölümü Öğretim Üyesi, hhbahar@erzincan.edu.tr
} 


\section{Meral, H. H. Bahar/Ë̈ Eğitim Fakültesi Dergisi,18-2(2016),1117-1134}

Anatolian High School and Imam Hatip High School. As the data collection tool, Problematic Internet Use Scale-Adolescent (PIUS-A), Psychological Well-Being Scale-Adolescent (PWBS-A) and UCLA Loneliness Scale were used. PIU scores were determined to significantly differ according to gender and school type. Gradeschool type common effect and gender-grade-school type common effect were found to be efficient upon PIU scores. Psychological Well-Being (PWB) and loneliness scores were specified to be significant predictors of PIU scores. Whereas PWB scores positively predicted PIU scores, loneliness scores negatively predicted PIU scores.

Key Words: Problematic Internet Use, Loneliness, Psychological Well-Being, Secondary Education Students

\section{Giriş}

İnternet dünya çapındaki bilgisayar sistemlerini birbirine bağlayan ve gittikçe gelişen bir iletişim ağıdır. Bu iletişim ağını düzenli olarak kullanan kişi sayısının hem dünyada (Spada 2014) hem de Türkiye'de (TUIKK 2015) giderek arttığı tespit edilmiştir. İnternetin okul çağındaki gençler tarafindan sıklıkla kullanılan bir iletişim ağı olması (TUİK 2014), özellikle orta ve yükseköğretim gençliğinde internet kullanımı ile ilgili birtakım problemlerin gündeme gelmesine sebep olmuş, konu ile ilgili çeşitli araştırmaların yapılmasına (Bayraktutan 2005; Ceyhan 2008; Esen ve Siyez 2011; Tarhan 2013; Çetin 2014; Çam 2014; Zorbaz ve Dost 2014; Yiğit 2015) kaynaklık etmiştir.

İnternet altyapısının hem teknolojik olarak gelişmesi hem de kullanıcı sayısının giderek artması birçok alanda günlük yaşamı kolaylaştırmaya yönelik firsatlar sağlasa da, birtakım problemleri de gündeme getirmektedir (Zorbaz ve Dost 2014; Yiğit 2015). Bu problemlerin bir bölümü günlük yaşam, kişisel gelişim, eğitim ve sağlı gibi alanlarla ilgilidir.

İnternet kullanımının yaygınlaşmaya başlaması ile birlikte yeni kavramlar ortaya çıkmaya başlamış, bu kavramlarla ilgili ölçme araçları geliştirilmiştir. Problemli İnternet Kullanımı (PIK) bunlardan birisidir. İlgili literatürde patolojik internet kullanımı, internet bağımlılığı gibi kavramların da kullanıldığı görülmektedir (Davis 2001; Caplan 2002; Spada 2014). İnternet bağımlılı̆̆ kontrol dışı ve zararlı kullanımını tanımlamak için kullanılan bir terimdir (Arısoy 2009). PİK internet ile ilişkili aşırı kullanımın 
D. Meral, H. H. Bahar/EÜ Eğitim Fakültesi Dergisi,18-2(2016),1117-1134

oluşturduğu problemleri ifade etmek için kullanılmaktadır (Ceyhan 2010). Beard and Wolf (2001) PIK'i, bireyin psikolojik ve sosyal yaşamı ile iş veya okul ortamında kendisine güçlükler oluşturan bir kullanım şekli olarak tanımlamaktadır. Bu olumsuz alışkanlığa sahip olan kişiler günlük işlerini erteleme veya ihmal etmenin yanı sıra, devamlı olarak internete odaklanmakta, aşırı kullanım sebebiyle kişisel gelişim, sağlık, sosyal etkileşim ve diğer konularda problemler yaşayabilmektedir (Ceyhan, 2010; Çağır ve Gürgan, 2010). İnternet bağımlılığı olan kişiler internetten yoksun kaldığında aşırı sinirlilik, saldırganlık gibi belirtiler sergileyebilmektedir (Young 2004).

Yalnızlık kavramı ile ilgili ortak bir tanım bulunmamakla birlikte, olumsuz özellikler yüklenen bir kavram olması konusunda görüş birliği olduğu söylenebilir. Evrensel, güçlü ve oldukça yaygın bir duygusal yaşantı olan yalnızlık istenmeyen, kaçınılmaya çalışılan, kayg1, öfke, üzüntü, stres gibi olumsuz duygularla ilişkili bir yaşantı olarak tanımlanmıştır (Doğan, Çetin ve Sungur 2009). Tanımlanması güç ve karmaşık bir durum olarak görülen yalnızlık, bireyin çevresine olan güvensizliğini artırarak uyumunu ve yaşamını zorlaştıran bir husus olarak görülmektedir (Seçim, Alpar ve Algür 2014). İnternetin yalnızlığa, yalnızlığın da internete yönelttiğine yönelik çalışmalar mevcuttur (Hamburger \& Artzi 2003; Whitty \& McLaughlin 2007). Balcı ve Gülnar'ın (2009) çalışmasında, evde yalnız yaşayan üniversite öğrencileri arasında riskli kullanıcı ve internet bağımlısı olma oranlarının diğerleri ile birlikte yaşayanlardan daha yüksek olduğu tespit edilmiştir.

Psikolojik İyi Oluş (PİO), farklı şekilde tanımlanan kavramlardan birisidir. Sirois (2011) PİO’yu genel yaşam kalitesi olarak tanımlamaktadır. Ryff'a (1995) göre PİO, stressiz olmaktan ya da diğer psikolojik problemlerin olmamasından çok daha fazlasını ifade etmektedir. PİO olumlu benlik algısını, insanlarla iyi ilişkileri, çevresel hakimiyeti, özerkliği, yaşamın anlamını ve sağlıklı bir gelişim yönündeki duyguları içermektedir. PİO ile ilgili iki farklı bakış açısının olduğu söylenebilir. Birincisi haz (hedonic), ikincisi ise psikolojik işlevsellik (eudaimonic) kavramlarıdır (Keyes, Shmotkin ve Ryff 2002; Ryan ve Deci, 2001). PİO özetle yaşam memnuniyeti olarak görülebilir. PİO’nun tanımına ilişkin farklı görüşler olsa da, kuramcılar PİO’nun bireyin pozitif işlevselliğine ilişkin bir kavram olduğu konusunda ortak bir anlayışa sahiptirler (Akın, 2009). 
İnternet bağımlılığı ergen ruh sağlığı açısından bir risk faktörü olarak görülmektedir (Ceyhan 2008). Bazı psiko sosyal bozuklukların da problemli internet kullanıcılarında daha yüksek oranda görüldüğü ifade edilmektedir (Shapira, Goldsmith, Keck, Khosla, \& McElroy 2000; Çam 2014). Çam (2014), PİK'in adölesanların yaşam şekillerini olumsuz yönde etkilendiğini, ayrıca bazı sosyo-demografik özelliklerin PİK yaygınlığını etkilediğini tespit etmiştir.

Yapılan bazı çalışmalar PİK'in yaygınlığı ile ilgili bazı sonuçlar ortaya çıkarmıştır. Çam'ın (2014) çalışmasında bu oran \% 7.1 bulunurken, diğer bir çalışmada (Aktepe, Dündar, Soyöz ve Sönmez 2013) \% 14.4, başka bir çalışmada (Canan, Yıldırım, Üstünel, Sinani, Kaleli, Güneş ve Ataoğlu 2014) ise \% 12.4 bulunmuştur. Balcı ve Gülnar'ın (2009) üniversite öğrencileri ile ilgili çalışmasında ise PİK oran $1 \% 51.6$ bulunmuştur.

Gençlerin psikolojik ihtiyaçlarını karşılama ve heyecan arama beklentileri onları PİK'e yöneltebilmektedir (Çetin ve Ceyhan 2015; Çetin 2014). İnternet kullanımının özellikle gençler arasında yaygınlaştığı günümüzde, ortaöğretim öğrencilerinin PİK ile yalnızlık ve PİO durumlarının incelenmesi önemli görülmektedir.

\section{Araştırmanın amact}

1. Cinsiyet, sınıf düzeyi ve okul türünün PİK'e etkisi var midir?

2. PİO ve yalnızlık, PİK'in anlamlı bir yordayıcısı mıdır?

\section{Çalışma grubu}

\section{Yöntem}

Çalışma grubu Doğu Karadeniz Bölgesindeki bir ilçe merkezindeki Anadolu Lisesi ve İmam Hatip Lisesinde öğrenim gören 242 ortaögretim öğrencisinden oluşmaktadır. Çalışma grubundaki öğrenciler 9, 10 ve 11 'nci sinıf öğrencileridir. Bu öğrencilerin 133'ü erkek, 109'u ise kız öğrencilerden oluşmaktadır.

\section{Veri toplama araçları}

Veri toplama aracı olarak kişisel bilgi formu, Problemli İnternet Kullanımı Ölçeği- Ergen (PİKÖ-E), Psikolojik İyi Oluş Ölçeği (PİOÖ-E), UCLA yalnızlık ölçeği kullanılmıştır. 
D. Meral, H. H. Bahar/Ë̈ Ĕğitim Fakültesi Dergisi,18-2(2016),1117-1134

\section{Kişisel bilgi formu}

Çalışma grubunun genel profillerini belirlemek amacı ile kullanılmıştır. Kişisel bilgi formunda katılımcıların cinsiyet, okul türü, interneti kullanım amacı, internet kullanım süresine ilişkin toplam dört soru bulunmaktadır.

\section{Problemli İnternet Kullanım Ölçeği-Ergen (PİKÖ-E):}

Problemli İnternet Kullanımı Ölçeği ilk olarak Ceyhan, Ceyhan ve Gürcan (2007) tarafindan üniversite öğrencilerinin problemli internet kullanım düzeylerini ölçmek üzere geliştirilmiştir. Ölçeğin ergenlere uyarlanan geçerlik ve güvenirlik çalışması Ceyhan ve Ceyhan (2014) tarafından yapılmıştır. İnternetin olumsuz sonuçları, aşırı kullanım ve sosyal fayda-sosyal rahatlık olmak üzere üç alt boyuttan oluşan ölçekte 27 madde bulunmaktadır. Ölçekle ilgili orijinal ölçekte (Ceyhan ve Ceyhan 2014) ve mevcut uygulamada tespit edilen iç tutarlılık katsayıları Tablo 1'de gösterilmiştir.

Tablo 1.PİKO-Ergen Ölçeğine İlişkin İç Tutarlılık Katsayıları

\begin{tabular}{lccc}
\hline Boyutlar & $\begin{array}{c}\text { Madde } \\
\text { Sayısı }\end{array}$ & $\begin{array}{c}\text { Orijinal Ölçek } \\
\text { (Ceyhan ve Ceyhan 2014) }\end{array}$ & $\begin{array}{c}\text { Mevcut Uygulama } \\
\text { (N: 242) }\end{array}$ \\
\hline İnternetin Olumsuz Sonuçları & 14 & .93 & .898 \\
Aşırı Kullanım & 6 & .76 & .730 \\
Sosyal Fayda-Sosyal Rahatlık & 7 & .78 & .769 \\
PİKO-E Ölçeğinin Tamamı & 27 & .93 & .924 \\
\hline
\end{tabular}

Mevcut uygulamada bulunan güvenirlik katsayılarının orijinal formun güvenirlik katsayılarına oldukça yakın olduğu görülmektedir. PİKO-E ölçeğine ilişkin bulunan iç tutarlılık katsayılarının, mevcut verilerin çalışma amacına yönelik olarak kullanılabileceğini göstermektedir.

\section{Psikolojik İyi Olma Ölçekleri Kısa Formu (PiOÖ):}

PİO düzeyini tespit etmek için Ryff (1989) tarafından geliştirilen ve Türkçe'ye uyarlanması Akın, Demirci, Yıldız, Gediksiz ve Eroğlu (2012) tarafından yapılan Psikolojik İyi Olma Ölçekleri'nin (PİOÖ) kısa formu kullanılmıştır. Bireyin kendisi hakkında bilgi vermesi esasına dayanan ölçek, PİO yapısının özelliklerini ölçmektedir. Ölçekte özerklik, çevresel hakimiyet, bireysel gelişim, 
D. Meral, H. H. Bahar/EÜ Eğitim Fakültesi Dergisi,18-2(2016),1117-1134

diğerleriyle olumlu ilişkiler, yaşam amaçları ve öz-kabul olmak üzere her biri yedi maddeden oluşan altı alt boyut bulunmaktadır. Ölçeğin kısa formunda toplam 42 madde bulunmaktadır. PİO ile ilgili analizler toplam puan üzerinden yapılmıştır. PİOÖ'nün mevcut uygulama için tespit edilen iç tutarlılık katsayısı .83'tür.

\section{UCLA Yalnızlık Ölçeği}

Katılımcıların yalnızlık düzeylerini tespit etmek için Demir (1990) tarafından geçerlilik ve güvenirlik çalışması yapılan UCLA Yalnızlık Ölçeği kullanılmıştır. Likert tipi kendini değerlendirme ölçeği olan UCLA yalnızlık ölçeği, bireyin genel yalnızlık derecesini belirler. Ölçekte toplam 20 madde bulunmaktadır. UCLA yalnızlık ölçeğinde de mevcut uygulama için iç tutarlılık katsayısı .83 bulunmuştur. Bir bireyin ölçekten yüksek puan alması, o bireyin daha fazla yalnızlık yaşadı̆̆ını gösterir.

\section{Verilerin Analizi}

Okul türü ve cinsiyetin PİK'e etkisini araştırmak için bağımsız faktöriyel ANOVA tekniği kullanılmıştır (Tabachnick \& Fidell 2015). PİO ve yalnızlığın PİK'in anlamlı bir yordayıcısı olup olmadığını belirlemek için çoklu doğrusal regresyon analizi tekniğinden yararlanılmıştır.

\section{Bulgular}

\section{Cinsiyet, sınıf düzeyi ve okul türünün PİK'e etkisi var mıdır?}

Çalışma grubundaki öğrencilerin cinsiyet, sınıf düzeyi ve okul türüne göre PIKK puan ortalama ve standart sapmaları Tablo 2'de gösterilmiştir. PİK'ten alınabilecek en yüksek ve en düşük puanlar 27 ile 135 arasında değişmektedir. 
D. Meral, H. H. Bahar/EÜ Eğitim Fakültesi Dergisi,18-2(2016),1117-1134

Tablo 2.Cinsiyet, Sinıf Düzeyi ve Okul Türüne Göre PİK Ortalama ve Standart Sapmaları

\begin{tabular}{|c|c|c|c|c|c|}
\hline Cinsiyet & Sinıf & Okul Türü & $\mathrm{N}$ & $\overline{\mathrm{X}}$ & Ss \\
\hline \multirow{13}{*}{ Kız } & \multirow{4}{*}{9} & Anadolu Lisesi & 22 & 48,23 & 15,19 \\
\hline & & İmam Hatip Lisesi & 29 & 55,55 & 14,97 \\
\hline & & Toplam & 51 & 52,39 & 15,36 \\
\hline & & Anadolu Lisesi & 21 & 47,71 & 15,86 \\
\hline & \multirow[t]{2}{*}{10} & İmam Hatip Lisesi & 18 & 45,11 & 18,28 \\
\hline & & Toplam & 39 & 46,51 & 16,84 \\
\hline & \multirow{4}{*}{11} & Anadolu Lisesi & 20 & 55,20 & 21,61 \\
\hline & & İmam Hatip Lisesi & 23 & 60,04 & 25,00 \\
\hline & & Toplam & 43 & 57,79 & 23,33 \\
\hline & & Anadolu Lisesi & 63 & 50,27 & 17,72 \\
\hline & \multirow[t]{3}{*}{ Toplam } & İmam Hatip Lisesi & 70 & 54,34 & 20,16 \\
\hline & & Toplam & 133 & 52,41 & 19,08 \\
\hline & & Anadolu Lisesi & 20 & 72,15 & 21,82 \\
\hline \multirow{10}{*}{ Erkek } & \multirow[t]{3}{*}{9} & İmam Hatip Lisesi & 22 & 57,73 & 17,11 \\
\hline & & Toplam & 42 & 64,60 & 20,58 \\
\hline & & Anadolu Lisesi & 16 & 48,81 & 19,04 \\
\hline & \multirow[t]{2}{*}{10} & İmam Hatip Lisesi & 15 & 72,67 & 20,45 \\
\hline & & Toplam & 31 & 60,35 & 22,88 \\
\hline & \multirow{4}{*}{11} & Anadolu Lisesi & 22 & 55,00 & 20,23 \\
\hline & & İmam Hatip Lisesi & 14 & 69,71 & 23,57 \\
\hline & & Toplam & 36 & 60,72 & 22,47 \\
\hline & & Anadolu Lisesi & 58 & 59,21 & 22,38 \\
\hline & \multirow{3}{*}{ Toplam } & İmam Hatip Lisesi & 51 & 65,41 & 20,77 \\
\hline \multirow{13}{*}{ Toplam } & & Toplam & 109 & 62,11 & 21,77 \\
\hline & & Anadolu Lisesi & 42 & 59,62 & 22,02 \\
\hline & \multirow[t]{3}{*}{9} & İmam Hatip Lisesi & 51 & 56,49 & 15,80 \\
\hline & & Toplam & 93 & 57,90 & 18,82 \\
\hline & & Anadolu Lisesi & 37 & 48,19 & 17,06 \\
\hline & \multirow[t]{3}{*}{10} & İmam Hatip Lisesi & 33 & 57,64 & 23,55 \\
\hline & & Toplam & 70 & 52,64 & 20,78 \\
\hline & & Anadolu Lisesi & 42 & 55,10 & 20,64 \\
\hline & \multirow[t]{3}{*}{11} & İmam Hatip Lisesi & 37 & 63,70 & 24,60 \\
\hline & & Toplam & 79 & 59,13 & 22,85 \\
\hline & & Anadolu Lisesi & 121 & 54,55 & $\mathbf{2 0 , 5 0}$ \\
\hline & \multirow[t]{2}{*}{ Toplam } & İmam Hatip Lisesi & 121 & 59,01 & 21,06 \\
\hline & & Toplam & 242 & 56,78 & 20,86 \\
\hline
\end{tabular}




\section{Meral, H. H. Bahar/Ë̈ Eğitim Fakültesi Dergisi,18-2(2016),1117-1134}

Çalışma grubundaki öğrencilerin alt boyutlara göre en düşük PİK puan ortalaması İHL onuncu sınıfına kayıtlı olan kız öğrencilere (45.11), alt boyutlara göre en yüksek PİK puan ortalaması ise İHL onuncu sınıfına kayıtlı olan erkek öğrencilere (72.67) aittir. Çalışma grubundaki öğrencilerin PİK puan ortalaması ise 56.78 olup ölçülebilecek en küçük değer olan 27 alt sınırına daha yakın gözükmektedir.

Tablo 3.Problemli İnternet Kullanımına Cinsiyet, Sınıf Düzeyi ve Okul Türünün Etkisine İlişkin Bağımsız Faktöriyel ANOVA Testi Sonuçları

\begin{tabular}{|c|c|c|c|c|c|c|}
\hline Source & $\begin{array}{c}\text { Type III } \\
\text { Sum of Squares }\end{array}$ & $\mathrm{df}$ & Mean Square & $\mathrm{F}$ & $\mathrm{p}$ & $\begin{array}{c}\text { Partial } \\
\eta^{2}\end{array}$ \\
\hline Corrected Model & $18082,595^{\mathrm{a}}$ & 11 & 1643,872 & 4,358 &, $000^{* * *}$ &, 172 \\
\hline Intercept & 765630,496 & 1 & 765630,496 & $\begin{array}{r}2029,6 \\
14\end{array}$ &, $000^{* *}$ & ,898 \\
\hline Cinsiyet & 6673,049 & 1 & 6673,049 & 17,690 &, $000^{* *}$ & 071 \\
\hline Sinif & 1607,838 & 2 & 803,919 & 2,131 &, 121 & 018 \\
\hline Okul türü & 1838,548 & 1 & 1838,548 & 4,874 &, $028^{*}$ & ,021 \\
\hline Cinsiyet *Sinıf & 1028,687 & 2 & 514,343 & 1,363 &, 258 & ,012 \\
\hline Cinsiyet $*$ Okul türü & 343,968 & 1 & 343,968 & ,912 & 341 & ,004 \\
\hline Sınıf* Okul türü & 2645,033 & 2 & 1322,517 & 3,506 &, $032^{*}$ &, 030 \\
\hline $\begin{array}{l}\text { Cinsiyet } * \text { Sinıf } * \text { Okul } \\
\text { türü }\end{array}$ & 6080,640 & 2 & 3040,320 & 8,060 &, $000^{* *}$ & ,065 \\
\hline Error & 86762,798 & 230 & 377,230 & & & \\
\hline Total & 885073,000 & 242 & & & & \\
\hline Corrected Total & 104845,393 & 241 & & & & \\
\hline
\end{tabular}

Cinsiyetin $\left(\mathrm{F}_{1-230}: 17.690, \mathrm{p}<.001, \mathrm{\eta}^{2}: .071\right)$, okul türü $\left(\mathrm{F}_{1-230}\right.$ : 4.874, $\left.\mathrm{p}<.05, \eta^{2}: .021\right)$, sinif-okul türü $\left(\mathrm{F}_{2-230}: 3.506, \mathrm{p}<.05, \eta^{2}\right.$ : .032) ile cinsiyet-sinıf ve okul türünün $\left(\mathrm{F}_{2-230}: 8.060, \mathrm{p}<.001, \eta^{2}\right.$ : .065) PİK'i etkilediği tespit edilmiştir. Sınıf $\left(\mathrm{F}_{2-230}: 2.131, \mathrm{p}>.05\right)$, cinsiyet-sinif $\left(\mathrm{F}_{2-230}: 1.363, \mathrm{p}>.05\right)$ ve cinsiyet-okul türünün $\left(\mathrm{F}_{2-230}\right.$ : $.912, \mathrm{p}>.05)$ ise PİK'i etkilemediği bulunmuştur. Kız öğrencilerin (52.41) erkek öğrencilerden (62.11), AL Öğrencilerinin (54.55) İHL öğrencilerinden (59.01) PİK puanı daha düşüktür. Dokuz (57.90), on (52.64) ve onbirinci (59.13) sinifların PİK puan ortalamaları arasındaki fark anlamlı bulunmamıştır. Diğer taraftan AL dokuz 
D. Meral, H. H. Bahar/Ë̈ Eğitim Fakültesi Dergisi,18-2(2016),1117-1134 (72.15), İHL on (72.67) ve İHL onbirinci (69.71) sinıf erkek öğrencilerinin yüksek PİK puanları dikkat çekmektedir.

PİO ve yalnızlı, PİK'in anlamlı bir yordayıcısı mıdır?

Tablo 4.PİO ve UCLA Puanlarının PİKO Puanlarını Yordamasına İlişkin Çoklu Doğrusal Regresyon Analizi Sonuçları

\begin{tabular}{|c|c|c|c|c|c|}
\hline \multirow[b]{2}{*}{ Değișkenler } & \multicolumn{3}{|c|}{ Standart } & \multirow[b]{2}{*}{$\mathrm{t}$} & \multirow[b]{2}{*}{$\mathrm{p}$} \\
\hline & B & Hata & $\beta$ & & \\
\hline (Sabit) & 97,225 & 13,564 & & 7,168 &, $000^{* *}$ \\
\hline PİO &,- 266 & ,050 &,- 360 & $-5,278$ &, $000^{* *}$ \\
\hline UCLA & ,312 & ,141 &, 151 & 2,210 &, $028^{*}$ \\
\hline $\begin{array}{l}\text { R: .459 } \\
\text { p }<.05\end{array}$ & $\begin{array}{c}\mathrm{R}^{2}: 211 \\
* * \mathrm{p}<.001\end{array}$ & $\overline{F_{2-239:}:}$ & $\overline{s<.0}$ & & \\
\hline
\end{tabular}

Tablo 4'te PİO ve UCLA puanlarının PİKO puanlarını yordama gücüne ilişkin çoklu doğrusal regresyon analizi sonuçları gösterilmiştir. Kurulan regresyon modelinin genel olarak anlamlı olduğu görülmektedir $\left(\mathrm{F}_{2-239:}\right.$ 31.955, $\left.\mathrm{p}<.001\right)$. PİO ve UCLA puanlarının PIKKO puanlarını anlamlı bir şekilde yordadığı bulunmuştur ( $\mathrm{R}: .459, \mathrm{R}^{2}$ : 211). PİO puanları $(\beta:-.360)$ PİKO puanlarını negatif yönde yordarken, UCLA puanları $(\beta$ : .151) PİKO puanlarını pozitif yönde yordamaktadır. Ayrıca, PIKO puanlarının yordanmasında PİO puanlarının UCLA puanlarından daha güçlü bir yordayıcı olduğu anlaşılmaktadır.

\section{Sonuç ve Tartışma}

\section{Okul türü ve cinsiyetin PİK'e etkisi var mıdır?}

Cinsiyet, okul türü, sınıf-okul türü ve cinsiyet-sınıf-okul türü PİK puanını etkilemektedir. Erkek öğrencilerin PİK puanı kız öğrencilerin PİK puanından, İmam Hatip Lisesi öğrencilerinin PİK puanları Anadolu Lisesi öğrencilerinin PIKK puanlarından yüksektir.

Mevcut çalışmada erkek öğrencilerin PIK puanı kız öğrencilerin PİK puanından yüksek bulunmuştur. İlgili literatürde, erkeklerin kızlara göre daha çok problemli internet kullanıcısı olduğunu destekleyen çalışmalar bulunmakla birlikte (Gürcan 2010; Üçkardeş 2010; Sevindik 2011; Sırakaya 2011; Türkoğlu 2013; 
D. Meral, H. H. Bahar/Ë̈ Eğitim Fakültesi Dergisi,18-2(2016),1117-1134

Y1lmaz 2013; Cicioğlu 2014; Durmuş ve Bașparmak 2014; Zorbaz ve Dost 2014; Beder 2015; İkiz, Asıc1, Savcı ve Yörük 2015), PİK puanının cinsiyete göre değişmediğine ilişkin bulgular da mevcuttur (Ceyhan 2010; Kurt 2014). Yılmaz'ın (2013) çalışmasında, cinsiyetin Pİ' in anlamlı bir yordayıcısı olduğu bulunmuştur. Üniversite öğrencileri ile ilgili yapılan bir çalışmada (İkiz, Asıcı, Savcı ve Yörük 2015), erkeklerde PİK'in daha yoğun olduğu bulunmuştur. Kızların erkeklere oranla internet kullanım oranlarının daha düşük olduğu tespit edilmiştir (Ayaroğlu 2002; Balta ve Horzum 2008). Ceyhan'ın (2010) çalışmasında ise problemli internet kullanımında cinsiyetin önemli bir faktör olmadığı bulunmuştur. İnterneti problemli kullanan üniversite öğrencilerinin psikolojik iyi oluşlarının interneti problemsiz kullanan öğrencilerin psikolojik iyi oluşlarından anlamlı biçimde daha düşük olduğu bulunmuştur (Yılmaz 2013). Erkek katılımcıların kadın katılımcılara göre daha s1k internet kullanmalarına rağmen, internet bağımlılığı üzerinde cinsiyetin ayırt edici bir etkisi bulunamamıştır (Balcı ve Gülnar 2009). Mevcut çalışmada PİK bakımından erkek öğrencilerin kız öğrencilere göre daha riskli bir konumda olduğu anlaşılmaktadır. Erkek öğrencilerde PİK puan ortalamasının daha yüksek olması, çalışma grubunda bulunan öğrencilerin bulunduğu sosyo-kültürel çevrede erkek öğrencilerin internet kullanımı konusunda kı öğrencilerden daha özgür bir ortamda bulunması etkili olabileceği gibi, PİK erkek öğrencilerin sahip olduğu cinsiyete dayalı özelliklerle de desteklenebilir. Bunların araştırılması ayrı bir çalışma konusu yapılabilir.

Dokuz ve onbirinci sınıf öğrencilerinin PİK puan ortalaması onuncu sinıf öğrencilerinin PİK puan ortalamasından yüksektir. Kurt (2014), Türkoğlu (2013) ve Gürcan'ın (2010) çalışmalarında sınıf düzeyine göre PİK puanlarının anlamlı bir farklılaşma göstermediği tespit edilirken; Beder'in (2015) çalışmasında güvenli internet kullanımı konusunda altıncı sınıf öğrencilerinin sekizinci sınıf öğrencilerinden daha bilinçli hareket ettiği bulunmuştur. Mevcut çalışmada, onuncu sınıf öğrencilerinin pik puanının en düşük düzeyde olduğu, onbirinci sınıfta bu ortalamanın en yüksek düzeye çıktığı anlaşılmaktadır. Onuncu sınıflar PİK puanı en düşük olan sınıflar olmakla birlikte; cinsiyet, sınıf düzeyi ve okul türü değişkenleri birlikte ele alındığında onuncu sınıf erkek öğrencilerinin en yüksek, 
onuncu sınıf kız öğrencilerinin de en düşük PİK puan ortalamasına sahip olması İHL grubunda cinsiyete dayalı PİK ayrışmasının en yüksek düzeyde olduğunu göstermektedir. Gerek benzer çalışmalar, gerekse mevcut çalışma sonuçları güvenli internet kullanımı konusunun ortaokul ve ortaögretim programlarında ele alınması gereken hususlardan birisi olduğu gerçeğini ortaya çıkarmaktadır.

İHL öğrencilerinin PİK konusunda AL öğrencilerinden daha sorunlu olduğu anlaşılmaktadır. Betimleyici istatistikler incelendiğinde, onuncu sınıfa kayıtlı olan erkek İHL öğrencilerin PİK kullanımı konusunda en sorunlu grup olduğu anlaşılmaktadır. Yapılan bir çalışmada (Gürcan 2010), meslek lisesinde öğrenim gören ergenlerin PİK'e ilişkin bazı alt boyut puanlarının Anadolu lisesinde öğrenim gören ergenlerin puanlarından daha yüksek bulunmuştur. Aynı çalışmada, genel lisede öğrenim gören öğrencilerin aşırı kullanım puanları imam hatip lisesi öğrencilerinin aşırı kullanım puanlarından yüksek bulunmuştur. Yapılan bir çalışmada (Türkoğlu 2013); okul türüne göre PİK puanlarının anlamlı bir farklılaşma göstermediği tespit edilmiştir. Öğretmen adaylarının PİK kullanımı ile ilgili yapılan bir çalışmada, PİK kullanım düzeylerinin kayıtlı olunan bölüme göre değişmediği tespit edilmiştir (Durmuş ve Beşparmak 2014).

\section{PİO ve yalnızlık, PíK'in anlamlı bir yordayıcısı mıdır?}

PİO ve UCLA puanları PİKO puanlarını anlamlı bir şekilde yordamaktadır. PİO puanları PİK puanlarını pozitif yönde yordarken, yalnızlık puanlarını negatif yönde yordamaktadır. PİK yalnızlığın hem sebebi hem de bir sonucu olarak düşünülebilir. PİK bireyi toplumdan uzaklaşarak yalnızlaştırabileceği gibi, yalnızlık da bireyin internete yönelmesine ve bireyi PİK'e sevk edebilir. Doğan'ın (2016) çalışmasında, sosyal ağ kullanımının mutluluk, psikolojik iyi oluş ve yaşam doyumunu anlamlı bir şekilde yordadığı tespit edilmiştir. Durualp ve Çiçekçioğlu'nun (2013) çalışmasında, internet bağımlılığının yalnızlık yaşayan bireyler arasında daha yüksek olduğu bulunmuştur. Yılmaz'ın (2013) çalışmasında, PİK'in PİO'nun anlamlı bir yordayıcısı olduğu bulunmuştur. İnterneti problemli kullanan üniversite öğrencilerinin PİO puanları interneti problemsiz kullanan 
D. Meral, H. H. Bahar/Ë̈ Eğitim Fakültesi Dergisi,18-2(2016),1117-1134

öğrencilerin PİO puanlarından daha düşük bulunmuştur. Yıldız'ın (2010) çalışmasında, PİO ile sağlıklı yaşam biçimi davranışları arasında negatif yönlü ilişki tespit edilmiştir. Yapılan bir çalışmada kendine ait bilgisayarı olan, yaşadığı yerde bilgisayar bağlantısı olan ve günde en az bir saat internete bağlanan üniversite öğrencilerinin yalnızlık puanlarının diğerlerinden yüksek olduğu bulunmuştur (Seçim, Alpar ve Algür 2014). Balcı ve Gülnar'ın (2009) araştırmasında, yalnızlığın internet bağımlılığını körükleyen bir unsur olarak ön plana çıktığı tespit edilmiştir. İnternet bağımlılarının daha uzun süre internet kullandığı ve internete daha fazla güven duyduğu görülmüştür. Yapılan bir çalışmada (Ayaroğlu 2002), yalnızlık puanı yüksek olan öğrencilerin internet kullanım oranlarının da yüksek olduğu bulunmuştur. Çetin ve Ceyhan'ın (2015) çalışmasında, yaşam doyumu niteliklerinin PİK'in önemli yodayıcılarından birisi olduğu tespit edilmiştir. Psikolojik ihtiyaçları karşılama ve heyecan arama beklentileri gençleri PİK'e yöneltebilmektedir (Çetin ve Ceyhan 2015; Çetin 2014). Mevcut çalışma grubunda da, benzer araştırma sonuçlarında ifade edildiği gibi, yalnızlık hisseden öğrencilerin yalnızlıklarını gidermek için interneti daha yoğun kullandığı, bunun da onları PİK'e sevkettiği düşünülmektedir. Ortaokul ve ortaöğretim programlarında öğretim etkinlikleri sürecinde gezi, gözlem, inceleme, grup çalışması, işbirliğine dayalı öğrenme etkinlikleri gibi birlikte yapılabilecek olan ögrenme etkinliklerine daha fazla yer verilebilir. $\mathrm{Bu}$ da öğrencinin öğrenme ile birlikte hem kendisini daha iyi hissetmesine hem de yalnızlı duygusunu azaltmasına katkı sağlayabilir. .

Sağlıklı internet kullanımı konusunda eğitimler verilebilir. Problemi henüz ortaya çıkmadan önlemek önemlidir. Bu bakımdan sağlıklı internet kullanımına ilişkin eğitimlerin lise yılları öncesinde başlanmasında ve ortaöğretim yıllarında da devam ettirilmesinde fayda görülmektedir. 
D. Meral, H. H. Bahar/Ë̈ Eğitim Fakültesi Dergisi,18-2(2016),1117-1134

\section{Kaynaklar}

Akın, A. (2009). Akılcı Duygusal Davranışçı Terapi (SDDT) odaklı grupla psikolojik danışmanın psikolojik iyi olma ve öz-duyarlık üzerindeki etkisi. Yayınlanmamış doktora tezi, Sakarya Üniversitesi Sosyal Bilimler Enstitüsü.

Akın, A., Demirci, İ., Yildiz, E., Gediksiz, E., \& Eroglu, N. (2012). The Short form of the Scales of Psychological Well-being (SPWB-42): The validity and reliability of the Turkish version. In International Counselling and Education Conference (pp. 3-5).

Aktepe, E., Dündar, N. O., Soyöz, Ö. ve Sönmez, Y. (2013). Possible internet addiction in high school students in the city center of Isparta and associated factors: a cross-sectional study. The Turkish Journal of Pediatrics, 55(4), 417-425.

Arısoy, Ö. (2009). İnternet bağımlılığı. Türkiye klinikleri journal of psychiatry special topics, 2(1), 75-83.

Ayaroğlu, N. S. (2002). The relationship between internet use and loneliness of university students. Yayınlanmamış yüksek lisans tezi, Orta Doğu Teknik Üniversitesi Sosyal Bilimler Enstitüsü.

Balc1, Ş., ve Gülnar, B. (2009). Üniversite öğrencileri arasında internet bağımlılı̆̆ ve internet bağımlılarının profili. Selçuk Üniversitesi İletişim Fakültesi Akademik Dergisi, 6(1), 5-22.

Balta, Ö. Ç. ve Horzum, M. B. (2008). Web tabanlı öğretim ortamındaki ögrencilerin internet bağımlılı̆̆ını etkileyen faktörler. Ankara Üniversitesi Eğitim Bilimleri Fakültesi Dergisi, 41(1), 187-205.

Bayraktutan, F. (2005). Aile içi ilişkiler açısından internet kullanımı, Yayımlanmamış yüksek lisans tezi, İstanbul Üniversitesi Sosyal Bilimler Enstitüsü.

Beard, K. W., \& Wolf, E. M. (2001). Modification in the proposed diagnostic criteria for Internet addiction. Cyber Psychology \& Behavior, 4(3), 377-383.

Beder, A. (2015). Ortaokul ögrencilerinin güvenli internet kullanım durumlarının belirlenmesi. Yayımlanmamış yüksek lisans tezi, Afyon Kocatepe Üniversitesi Fen Bilimleri Enstitüsü.

Çağır, G., ve Gürgân, U.(2010). Lise ve üniversite öğrencilerinin problemli internet kullanım düzeyleri ile algılanan iyilik halleri ve yalnızlı düzeyleri arasındaki ilişski. Balıkesir Üniversitesi Sosyal Bilimler Enstitüsü Dergisi, 13(24) 70-85.

Çam, H. H. (2014). Adölesanlarda internet bağımlıllğı prevalanst ile psikopatolojik semptomlar ve obezite arasındaki ilişkinin incelenmesi. Yayımlanmamış doktora tezi, Cumhuriyet Üniversitesi Sağlık Bilimleri Enstitüsü. 


\section{Meral, H. H. Bahar/Ë̈ Eğitim Fakültesi Dergisi,18-2(2016),1117-1134}

Canan, F., Yildirim, O., Ustunel, T. Y., Sinani, G., Kaleli, A. H., Gunes, C., \& Ataoglu, A. (2014). The relationship between internet addiction and body mass index in Turkish adolescents. Cyberpsychology, Behavior, and Social Networking, 17(1), 40-45.

Caplan, S.E. (2002). Problematic Internet use and psychosocial well-being: development of a the orybased cognitive-behavioral measure. Computers in Human Behavior 18:533-575.

Çetin, A. B. ve Ceyhan, A. A. (2015). Ergenlerin internette kimlik denemeleri ve problemli internet kullanım davranışları, Addicta: The Turkish Journal on Addiction, 1 (2), 5-46.

Çetin, A.B. (2014). Ergenlerin internet ve problemli internet kullanım davranışlarının bazı psiko-sosyal özellikler açısından incelenmes. Yayımlanmamış doktora tezi, Anadolu Üniversitesi Eğitim Bilimleri Enstitüsü.

Ceyhan E. , Ceyhan A.A. ve Gürcan, A. (2007).Problemli İnternet Kullanımı Ölçeği’nin Geçerlik Ve Güvenirlik Çalışmaları. Kuram ve Uygulamada Ĕgitim Bilimleri (KUYEB) Dergisi, 7, 387-416.

Ceyhan, A. A. ve Ceyhan, E. (2014). Problemli İnternet Kullanım Ölçeği’nin geçerlik ve güvenirlik çalışması, Bă̆ımlılık Dergisi, 15 (2), 56-64.

Ceyhan, E. (2008). Ergen ruh sağlığı açısından bir risk faktörü: İnternet bağımlılı̆̆ı. Çocuk ve Gençlik Ruh Sağliğı Dergisi, 15(2), 109-116.

Ceyhan, E. (2010). Problemli internet kullanım düzeyi üzerinde kimlik statüsünün, internet kullanım amacının ve cinsiyetin yordayıcılığı. Kuram ve Uygulamada Eğitim Bilimleri, 10(3), 1323-1355.

Cicioğlu, M. (2104). Öğrencilerin problemli internet kullanımı ve siber zorbalık davranışlarına ilişkin görüşleri, Yayımlanmamış yüksek lisans tezi. Abant İzzet Baysal Üniversitesi Eğitim Bilimleri Enstitüsü.

Davis, R. A. (2001). A cognitive-behavioral model of pathological Internet use. Computers in Human Behavior, 17(2), 187-195.

Demir, A. (1990). Üniversite öğrencilerinin yalnızlık düzeylerini etkileyen bazı etmenler. Yayınlanmamış doktora tezi. Hacettepe Üniversitesi Sosyal Bilimler Enstitüsü.

Doğan, T., Çetin, B., ve Sungur, M. Z. (2009). İş yaşamında yalnızlık ölçeği Türkçe formunun geçerlilik ve güvenilirlik çalışması. Anadolu Psikiyatri Dergisi,10(6), 271-277.

Doğan, U. (2016). Lise öğrencilerinin sosyal ağ siteleri kullanımının mutluluk, psikolojik iyi-oluş ve yaşam doyumlarına etkisi: Facebook ve twitter örneği. Eğitim ve Bilim, 41(183). 


\section{Meral, H. H. Bahar/Ë̈ Eğitim Fakültesi Dergisi,18-2(2016),1117-1134}

Durmuş, A. ve Başarmak, U. (2014). Öğretmen adaylarının eğitsel internet kullanım öz-yeterlik inançları ve problemli internet kullanım durumları arasındaki ilişkinin incelenmesi. Ahi Evran Üniversitesi Kırş̧ehir Eğitim Fakültesi Dergisi, 15(3).

Durualp, E., \& Çiçekoğlu, P. (2013). Yetiştirme yurdunda kalan ergenlerin yalnızlık düzeylerinin internet bağımlılı̆̆ ve çeşitli değişkenler açısından incelenmesi. Dokuz Eylül Üniversitesi Sosyal Bilimler Enstitüsü Dergisi, 15(1), 29-46.

Esen, E. ve Siyez, D.M.(2011) Ergenlerde internet bağımlılığını yordayan psikososyal değişkenlerin incelenmesi. Türk Psikolojik Danışma ve Rehberlik Dergisi, 4 (36), 127-138.

Gürcan, N. (2010). Ergenlerin problemli internet kullanımlart ile uyumlart arasındaki ilişkinin incelenmesi, Yayımlanmamış Yüksek Lisans Tezi, Selçuk Üniversitesi Eğitim Bilimleri Enstitüsü.

Hamburger, Y. A. \& Artzi, E. B. (2003). Loneliness ant internet use, Computers in Human Behavior, 19 (1), 71-80.

İkiz, E., Asıc1, E., Savcı, M., ve Yörük, C. (2015). Problemli internet kullanımı ile üniversite yaşamına uyum ilişkisi. Bartın Üniversitesi Eğitim Fakültesi Dergisi, 4(1), 34-50.

Keyes, C. L., Shmotkin, D., \& Ryff, C. D. (2002). Optimizing well-being: the empirical encounter of two traditions. Journal of Personality and Social Psychology, 82(6), 1007-1022

Kurt, N. Ö. (2014). Meslek lisesi ögrencilerinde problemli internet kullanımı, bilişsel yetenek ve dikkat becerilerinin incelenmesi, Yayımlanmamış yüksek lisans tezi, Ege Üniversitesi Sağllk Bilimleri Enstitüsü.

Ryan, R. M., \& Deci, E. L. (2001). On happiness and human potentials: A review of research on hedonic and eudaimonic well-being. Annual Review of Psychology, 52(1), 141-166.

Ryff, C. D. (1989). Happiness is everything, or is it? Explorations on the meaning of psychological well-being. Journal of Personality and Social Psychology, 57(6), 1069-1081.

Ryff, C. D. (1995). Psychological well-being in adult life. Current Directions in Psychological Science, 4(4), 99-104.

Seçim, Ö. Y., Alpar, Ö., ve Algür, S. (2014). Üniversite öğrencilerinde yalnızlık: Akdeniz üniversitesinde yapılan ampirik bir araştırma. Elektronik Sosyal Bilimler Dergisi, 48(48).

Sevindik, F. (2011). Firat Üniversitesi ögrencilerinde problemli internet kullanımı ve sağlıkl yaşam biçimi davranışlarının belirlenmesi. Yayımlanmamış doktora tezi. İnönü Üniversitesi Sağlık Bilimleri Enstitüsü. 


\section{Meral, H. H. Bahar/Ë̈ Eğitim Fakültesi Dergisi,18-2(2016),1117-1134}

Shapira, N. A., Goldsmith, T. D., Keck, P. E. Jr., Khosla, U. M. and McElroy, S. L. (2000). Psychiatric features of individuals with problematic internet use, Journal of Affective Disorders, 57(1-3), 267-272.

Sırakaya, M. (2011). Öğretmen adaylarının problemli internet kullanımı ve internet özyeterlik düzeylerinin incelenmesi. Yayımlanmamış Yüksek Lisans Tezi, Hacettepe Üniversitesi Fen Bilimleri Enstitüsü.

Sirois, F. (2011). Psychological health and well-being: A research agenda for the Eastern Townships. Journal of Eastern Townships Studies, (37), 77.

Spada, M. M. (2014). An overview of problematic Internet use. Addictive Behaviors, 39(1), 3-6.

Tabachnick, B. G. and Fidell, L. S. (2015). Using Multivariate Statistics (Sixth edition). (M. Baloğlu, Çev.). Ankara: Nobel Yayınevi. (Original work published 2012).

Tarhan, T. (2013). Ergenlerde depresyon düzeylerinin internet kullanım amaçları ve akademik başarı açısından incelenmesi. Yayımlanmamış yüksek lisans tezi, İstanbul Arel Üniversitesi Sosyal Bilimler Enstitüsü.

Türkiye İstatistik Kurumu (TUIK). (2014). Hanehalkı bilişim teknolojileri kullanımı araştırmas1. http://www.tuik.gov.tr/OncekiHBArama.do adresinden $\underline{02.4 .2016}$ tarihinde indirilmiştir.

Türkiye İstatistik Kurumu (TUİK). (2015). Hanehalkı bilişim teknolojileri kullanımı araştırması. http://www.tuik.gov.tr/OncekiHBArama.do adresinden 02.4.2016 tarihinde indirilmiştir.

Türkoğlu, S. (2013). Ergenlerin problemli internet kullanımlarl ile siber zorbalık eğilimleri arasındaki ilişkinin incelenmesi. Yayımlanmamış yüksek lisans tezi, Marmara Üniversitesi Eğitim Bilimleri Enstitüsü.

Üçkardeş, E. A. (2010) Mersin Üniversitesi öğrencileri arasında internet bağımlılığının değerlendirilmesi. Yayımlanmamış uzmanlık tezi, Mersin Üniversitesi Tıp Fakültesi.

Whitty, M. T., \& McLaughlin, D. (2007). Online recreation: The relationship between loneliness, Internet self-efficacy and the use of the Internet for entertainment purposes. Computers in Human Behavior, 23(3), 1435-1446.

Yiğit, Z. (2015). 13-18 yaş aralı̆̆ındaki ergenlerde, problemli internet kullanımı, öz anlayış ve iletişim becerileri arasındaki ilişkinin incelenmesi. Yayımlanmamış yüksek lisans tezi, İstanbul Arel Üniversitesi Sosyal Bilimler Enstitüsü.

Yıldız, İ. (2010), Lise ögrencilerinde problemli internet kullanımı ile sağllklı yaşam biçimi davranışları arasındaki ilişki. Yayımlanmamış yüksek lisans tezi. Cumhuriyet Üniversitesi Sağlık Bilimleri Enstitüsü. 
D. Meral, H. H. Bahar/Ë̈ Eğitim Fakültesi Dergisi,18-2(2016),1117-1134

Yılmaz, M. F. (2013). Üniversite öğrencilerinin psikolojik iyi oluşlarının problemli internet kullanımı ve bazı demografik değişkenler açısından incelenmesi. Yayımlanmamış yüksek lisans tezi, Anadolu Üniversitesi Eğitim Bilimleri Enstitüsü.

Young, K. S. (2004). Internet addiction a new clinical phenomenon and its consequences. American Behavioral Scientist, 48(4), 402-415.

Zorbaz, O. ve Dost, M. T. (2014). Lise öğrencilerinin problemli internet kullanımının cinsiyet, sosyal kaygı ve akran ilişkileri açısından incelenmesi. Hacettepe Üniversitesi Ĕ̈itim Fakültesi Dergisi, 29(29-1).

\section{Extended Summary}

\section{Purpose}

Internet is a communication network that is developing gradually and connecting computer systems all around the world to each other. The number of individuals using this communication network regularly has gradually increased. School youth has a remarkable place in this increase. Secure internet use has become a current issue through the internet use of the young. One of the concepts developed on the issue is Problematic Internet Use (PIU). In this research, whether school type, gender and grade level were efficient upon PIU scores was investigated. Furthermore, whether Psychological Well-Being (PWB) and loneliness were significant predictors of PIU or not was also analyzed.

\section{Method}

As the data collection tool, Problematic Internet Use Scale-Adolescent (PIUS-A), Psychological Well-Being Scale-Adolescent (PWBS-A) and UCLA Loneliness Scale were used beside the personal information form. In personal information form, information related to grade level, gender and school type was included. PWBS was firstly developed by Ceyhan, Ceyhan and Gürcan (2007) in order to measure the problematic Internet use levels of the university students. Reliability and validity study of the scale adapted to adolescents was carried out by Ceyhan and Ceyhan (2014). In order to determine Psychological Well-Being (PWB) level, PWBS short form developed by Ryff (1989) and adapted into Turkish by Akın, Demirci, Yıldız, Gediksiz and Eroğlu (2012) was used. UCLA Loneliness Scale was used in order to determine the loneliness levels of the participants; validity and reliability study of the scale was carried out by Demir (1990). Reliability coefficients determined for the scales in the current study were .92 for PIUS-A, .83 for UCLA. Independent factorial ANOVA technique was used to investigate the effect of school type and gender upon PIU (Tabachnick \& Fidell, 2015). In order to determine whether PWB and loneliness were significant predictors of PIU, multiple linear regression analysis technique was benefited.

\section{Results}

According to the research results, gender, school type, grade-school type and gender-school type-grade were significant variables upon determining the PIU 


\section{Meral, H. H. Bahar/Ë̈ Eğitim Fakültesi Dergisi,18-2(2016),1117-1134}

scores. PIU score of male students were higher than the PIU scores of female students; and PIU scores of Imam Hatip High School students were higher than the PIU scores of the Anatolian High School students. In this study group, male students were understood to be more risky rather than the female students in terms of PIU. PWB and UCLA scores significantly predicted PIUS-A scores. Whereas PWB scores positively predicted PIU scores, PWB scores predicted the loneliness scores negatively.

\section{Discussion and Conclusion}

In the study group, male students' being in a more free environment rather than the female students in terms of internet use in their socio-cultural surrounding could be efficient upon male students' having higher PIU scores; and gender-based characteristics male students had were possible to support high PIU scores. Investigation of these could be another research subject. According to the level of grade, PIU score average of the ninth and eleventh grade students was higher than the PIU score average of the tenth grade students. In data analysis, it was understood that PIU score of the tenth grade students was at the lowest level, and this average was at its highest level in the eleventh grade. The tenth grade was the one with the lowest PIU score; furthermore, when gender, grade level and school type variables were considered together, tenth grade male students' having the highest and tenth grade female students' having the lowest PIU score average proved that genderbased PIU score differentiation was at the highest level in Imam Hatip High School group. The results of both similar studies and this study revealed the fact that the secure internet use was one of the issues to be discussed in secondary education curriculums. Imam Hatip High School students were noticed to have more problematic rather than the Anatolian High School students in terms of PIU. When descriptive statistics were analyzed, male Imam Hatip High School students studying at the tenth grade were understood to be creating the most problematic group in terms of PIU use.

PIU could be considered as both cause and result of loneliness. PIU could isolate individuals secluding from the society, and loneliness could lead them to PIU and using the Internet. In the current study group similar research results were mentioned, and it was considered that the students feeling loneliness used the Internet more in order to relieve their loneliness and this led them to PIU. In secondary education curriculums, learning activities that were possible to be performed together such as visits, observations, investigative visits, group works, and cooperation-based learning activities could be included more during the educational activities process. And this could provide contribution upon learning of students and their feeling themselves better at a decrease in their feeling of loneliness. Trainings could be held on healthy internet use. It is important to overcome a problem without it emerges. In this sense, it was considered beneficial to start trainings related to the Internet use before high school period, and maintain in secondary education process. 